\begin{tabular}{|c|c|}
\hline 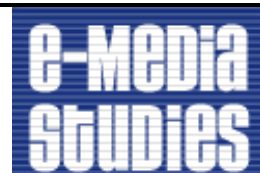 & $\begin{array}{l}\text { Journal of e-Media Studies } \\
\text { Volume 3, Issue 1, } 2013 \\
\text { Dartmouth College }\end{array}$ \\
\hline
\end{tabular}

\title{
Can Digital Humanities Mean Transformative Critique?
}

Alexis Lothian and Amanda Phillips

We need new hybrid practitioners: artist-theorists, programming humanists, activistscholars; theoretical archivists, critical race coders. We need new forms of graduate and undergraduate education that hone both critical and digital literacies. We have to shake ourselves out of our small, field-based boxes so that we might take seriously the possibility that our own knowledge practices are normalized, modular, and black boxed in much the same way as the code we study in our work.

—Tara McPherson, "Why is the Digital Humanities So White?" (154)

We were invited to this issue of the Journal of e-Media Studies because we gave something a name. We are two participants in a group of early-career queer, feminist, and ethnic studies scholars of media, literature, and culture who are interested in digital scholarship, who kept meeting at conferences and wondering why the critical frameworks and politicized histories of our activist inquiry were so rarely part of the conversations we were having about scholarly technology. The series of academic conference events that led us to converge as a collective have by now been hashed and rehashed many times: there was an idea at THATCamp SoCal in response to anxiety at MLA 2011; then a small but productive panel at ASA (American Studies Association) 2011; some blog posts on HASTAC (Humanities, Arts, Sciences, and Technology 
Advanced Collaboratory) and elsewhere, a Tumblr; and the birth of a hashtag that finally caught the attention of the digital humanities (DH) Twittersphere. Somebody made a Google Doc, some bodies attended a panel, and some buddies were in the collective hoping that people would take over the hashtag and submit to the Tumblr and blog about why \#transformDH was cute but vague and ultimately misguided. But, ultimately, the project's goal was to put a name to a feeling and see who else was thinking the same thing. That there are now names out there, records of attendance, email trails, and other evidence for the future tenure files that might take such endeavors into account, was a side effect that has taught us much about the power of namingyou might even say of branding — when you want to get an idea into circulation.

What was the idea? In short, \#transformDH is an aggregated statement of the obvious. First of all: the emergent methods and practices we call digital humanities are not only for traditional work. Years of DH criticism might point to the banality of this sentiment; the changing shapes of communication and technology alter the terms of scholarship, and keeping afloat in the coming century will require mastery over new tools and methods. The revolution of DH is in full swing, with the force of multicampus institutions, internet portals, and federal funding at its back. The histories that $\mathrm{DH}$ as a discipline traces back through practices of humanities computing have indeed done transformational work on the structures of scholarship and the bureaucracies that shape our careers. Yet the bright lights and marching bands of the so-called big tent outshine less marketable histories of engagement with technology that have emerged from standpoints that critique the privileging of certain gendered, racialized, classed, able-bodied, Western-centric productions of knowledge. In a recent blog entry, filmmaker, feminist, and academic Alex Juhasz describes why she does not affiliate herself wholeheartedly with digital humanities: 
The "field" does the amazing potentially radicalizing work of asking humanities professors (and students) to take account for their audiences, commitments, forms, and the uses of their work. But this was always there to take account of, being obscured by the transparent protocols of publishing and pedagogy that have been revealed because of the force of the digital. However, this turn is occurring, for the most part, as if plenty of fields, and professors, and artists, and students, and humanists hadn't been already been doing this for years (and therefore without turning to these necessarily radical traditions of political scholars, theoretical artists, and humanities activists).

\#TransformDH was our attempt to turn the digital humanities toward these radical traditions, as well as toward the bodies of critical work in new media studies by Wendy Chun, Lisa Nakamura, Anna Everett, Tara McPherson, and many others, that unpack the politics inherent in the force of the digital, the powers that shape the hardware and software that in turn shape our scholarly work. We wanted to think about the institutions that were forming in this ever more amorphous thing called digital humanities. We didn't want the ways of engaging knowledge that were important to us to be left out. We felt it would be too easy to say that we were doing something other than DH, whether that be new media studies or critical cultural studies with a focus on the digital; instead, we wanted to bring what Juhasz calls "necessarily radical traditions," which have nourished us, into the DH field in which we also felt at home. If humanities scholars in critical media and cultural studies, queer studies, ethnic studies, disability studies, and related areas are doing work in and with the digital, we should lay claim to our place within digital humanities. We should explicitly occupy that space and assert — as McPherson and Jamie "Skye" Bianco, 
among others, have recently done - that the honorable history of humanities computing is not the only one that matters for whatever it is we mean when we talk about the field.

Inclusivity is important to $\mathrm{DH}$ practitioners in the humanities computing tradition. We share that goal, but it is not the heart of our project. In "Whose Revolution? Towards a More Equitable Digital Humanities," Matthew K. Gold's MLA 2012 talk reflecting on his book Debates in the Digital Humanities, Gold raises the question of which hierarchies, uneven distributions of labor, and value systems DH might preserve even as it seeks to change the way academic work is done. His important discussion focuses on the vital and often overlooked power of institutional resources to shape what scholarly work gets done. Yet the metaphor that comes after his set of concrete and useful suggestions for diversifying DH is interesting: "as any software engineer can tell you, the more eyes you have on a problem, the more likely you are to find and fix bugs in the system." If the system of DH were to run smoothly, Gold implies, it would not perpetuate hierarchies or inequalities. Gender, race, sexuality, ability, and class-and the marked bodies on which they become most visible — can be content that would fit within the forms already being established and funded for digital work: the on-campus centers, the annotated archives. But what we know about the academy, from its constitutive imbrications with nationalism and empire to the structures of race and gender that still shape its labor practices, suggests otherwise. Content and form are not so separable; truly accounting for one will unavoidably change the other.

So instead of smoothing out the bugs in the digital academy, we wonder how digital practices and projects might participate in more radical processes of transformation — might rattle the poles of the big tent rather than slip seamlessly into it. To that end, we are interested in digital 
scholarship that takes aim at the more deeply rooted traditions of the academy: its commitment to the works of white men, living and dead; its overvaluation of Western and colonial perspectives on (and in) culture; its reproduction of heteropatriarchal generational structures. Perhaps we should inhabit, rather than eradicate, the status of bugs — even of viruses - in the system. Perhaps there are different systems and anti-systems to be found: DIY projects, projects that don't only belong to the academy, projects that still matter even if they aren't funded, even if they fail.

What would digital scholarship and the humanities disciplines be like if they centered around processes and possibilities of social and cultural transformation as well as institutional preservation? If they centered around questions of labor, race, gender, and justice at personal, local, and global scales? If their practitioners considered not only how the academy might reach out to underserved communities, but also how the kinds of knowledge production nurtured elsewhere could transform the academy itself? These questions are not hypothetical. These digital humanities already exist. Here we offer a curated list of projects, people, and collaborations that suggest the possibilities of a transformative digital humanities: one where neither the digital nor the humanities will be terms taken for granted.

The transformative digital humanities will not be found only among the members of our ad hoc collective. Nor will it be found only where the funding is, where the easily recognized and intensively supported DH projects are. We've gathered a selection of projects, ranging from institutionally sponsored archives of less-than-traditional materials to networks that purposefully have no direct connection to the academy as such. None belongs to a core member of our 
collective, because we are becoming a little alarmed at the publicity our act of naming has begun to generate. All the projects put the questions of decades of feminist, queer, and critical race theory (all of which share significant temporal nodes with the politicized computing movements at the heart of much DH philosophy) at the center of their work, leveraging the affordances and methodologies for social justice. Here one can find collaboration pushed to collectivity, interdisciplinarity that reaches outside of the ivory tower, and art that builds its own theory. These are only beginnings, suggestions; you may disagree that these are projects worth gathering, or you may wish to suggest other projects for consideration. Your feedback, critiques, and additions will help us to build a transformative digital humanities together.

\section{Curation}

\section{Transformative Archives}

Archives may be the most legible form of digital humanities production, as digital tools have been developed to preserve, gather, and share historical documents. Digital humanities practitioners have increasingly been theorizing the power structures and silences of the archive, as well as drawing on materials less often granted the legitimacy of academic preservation. 


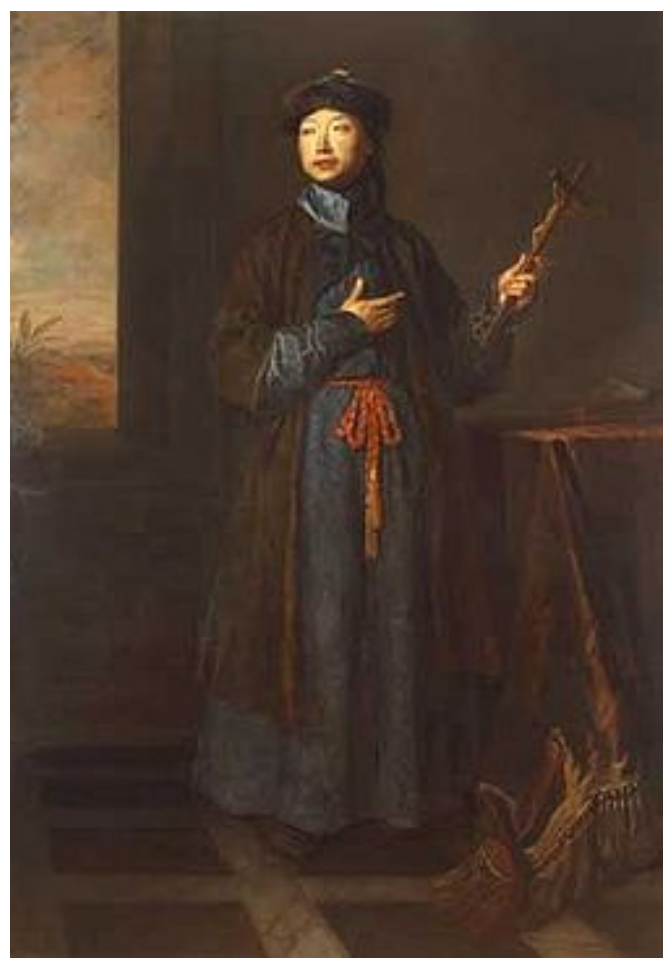

Adeline Koh: Digitizing "Chinese Englishmen": Representations of Race and Empire in the Nineteenth Century

Adeline Koh's online Digitizing "Chinese Englishmen" project is an early step in the direction of decolonizing the archive, offering a forum for collaborative annotation and novel social media intervention on texts that expand the Victorian Anglophone repertoire beyond its current "narrow geographical boundaries." Koh's project carves out a space for the postcolonial archive:

The website is meant to be both a "decentralized" and a "postcolonial" archive. By a "decentralized" archive, it refers to one which provides modes for democratic access and exchange. On first glance, the term "postcolonial" nineteenth century archive may appear anachronistic, as no colonies were in fact "postcolonial" in this time period. My use of the term "postcolonial," however, derives more from the type of postcolonial 
literary criticism and postcolonial theory commonly associated with Edward Said and the Subaltern Studies Collective than with movements towards decolonization before and after the Second World War.

In this definition, a "postcolonial" archive is one which examines and questions the creation of imperialist ideology within the structure of the archive. Additionally, it aims to assemble a previously unrepresented collection of subaltern artifacts. ("Addressing Archival Silence on 19th Century Colonialism - Part 2")

Straits Chinese Magazine, the project's source text, offers readers a complicated, alternative view of what it meant to be both an Englishman and a Chinese gentleman in the 19th century. Koh's archive makes no effort to resolve or simplify the complicated identity practices of the Chinese Englishmen, hoping instead to offer a platform to evaluate them without the colonial impulse to reduce these Victorians to paragons of false consciousness or imitations of "real" British gentlemanliness. Digitizing "Chinese Englishmen" expands the archive beyond colonial representations of nonwhite peoples in the 19th century, leveraging the reach of the digital to transform the face of 19th-century studies. 


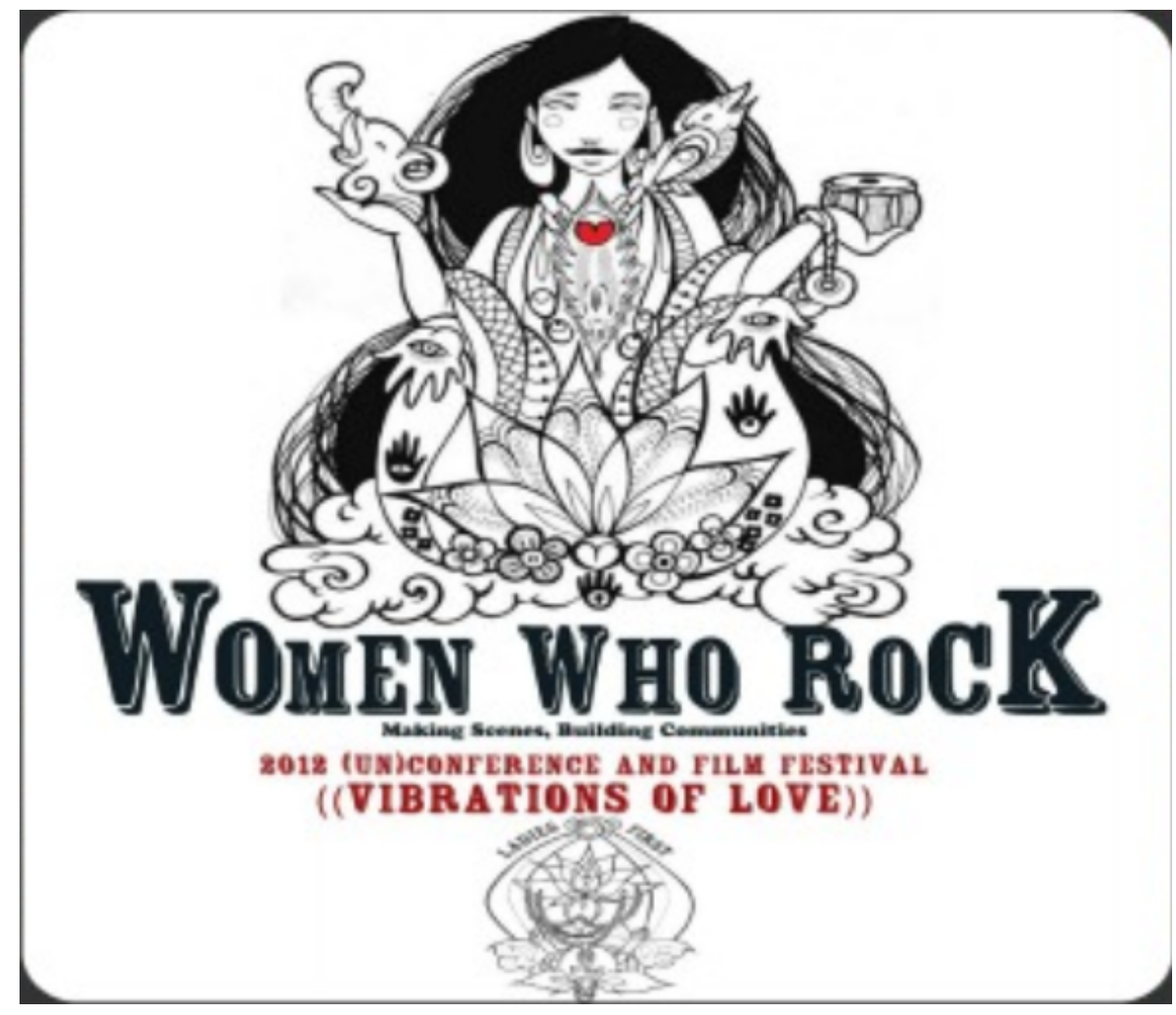

Women Who Rock: Making Scenes, Building Communities at the University of Washington

Women Who Rock is an oral history archive at the University of Washington, built from the ground up on the principles of women of color feminism: collaboration across difference, intersectional critique, and accountability to communities outside the academy. Participation in the project provides training for women's and ethnic studies graduate students in the digital skills that suit their research interests, from web design to video production. Headed by Michelle Habell-Pallán, this is one of the few well-established, institutionally supported DH projects that are rooted in critical feminist media theory and praxis.

Women Who Rock Research Project (WWRRP) supports, develops, and circulates cultural production, conversations and scholarship by cultural producers and faculty, 
graduate students, and undergraduates across disciplines, both within and outside the University, who examine the politics of gender, race, class, and sexuality generated by popular music. Our goal is to generate dialogue and provide a focal point from which to build and strengthen relationships between local musicians and their communities, and educational institutions. (Women Who Rock Project: Making Scenes, Building

\section{Communities)}

[Video by Angelica Macklin: http://vimeo.com/24484214]

Oral histories such as this are committed to the production of knowledge from below, bringing people and practices who have traditionally been excluded from academic spheres—or simply not taken seriously there-into the frameworks of institutional preservation. In the case of Women Who Rock, the preservation of popular music's communities and histories is also aimed at a transformation of the institutional archive itself, bringing down barriers between the university and the knowledge worlds that lie outside its walls.

\section{Transformative Artistic Production}

Definitions of the digital humanities do not often include digital artistic production. But why not? The borders of artistic practice, software design, political activism, and critical knowledge production are porous. 


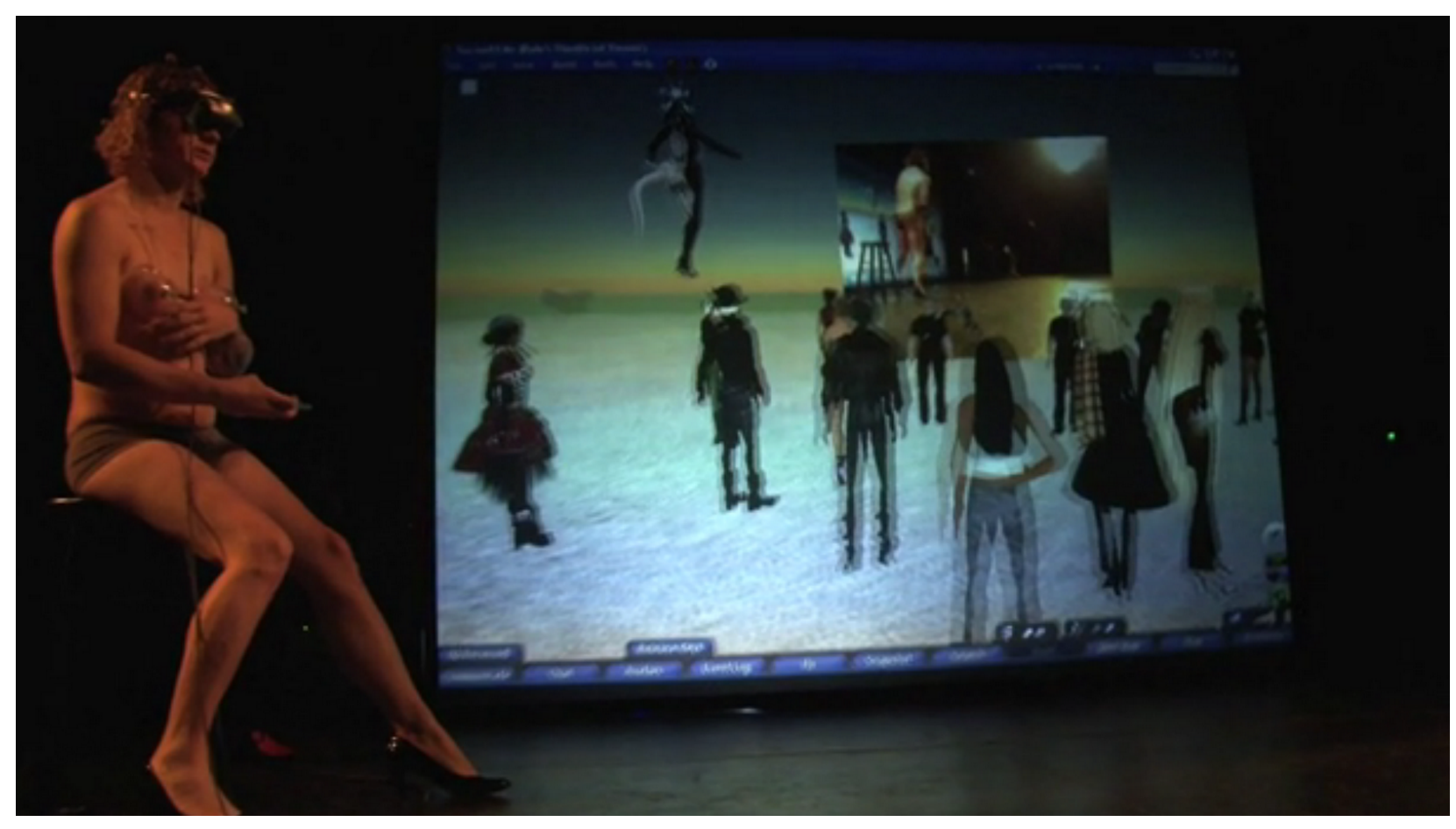

\section{Micha Cárdenas: Transreal Politics}

A queer performance artist currently working toward a $\mathrm{PhD}$ in the University of Southern California (USC)'s Interactive Media Arts and Practice program, Micha Cárdenas uses art, theory, and technology to encourage social justice thinking, which results in a unique brand of art-theory that pushes each of the fields in which it engages. Cárdenas develops new software applications, designs and builds electronic gadgets that challenge hegemonic regimes, and infuses each performance with theoretical writing. Cárdenas's collaborative work has resulted in two theoretical texts so far: Trans Desire/Affective Cyborgs, coauthored by Barbara Fornssler and Wolfgang Shirmacher, and The Transreal: Political Aesthetics of Crossing Realities, coauthored with Zach Blas, Elle Mehrmand, and Amy Sara Carroll. Cárdenas's work takes transto its fullest extent, crossing realities, genders, theoretical perspectives, and technical design. 
The video featured here, "Becoming Transreal," a performance in collaboration with Elle Mehrmand and Chris Head, focuses the attention of the digital back on the material body and its entanglement with global capital, reminding us, through the pain of transgender experience braided with a dystopic science fiction narrative, that technology is of concern to bodies (and corporations) most of all. From the video's description:

What if you could become anything? What happens after species change surgery becomes a reality? becoming transreal speculates on a future in which the promises of bionanotechnology have become realized, and yet as capitalism has continued to fail, both the interiors of our bodies and the virtual world have become totally commodified. you can become anything, but to finance your whims of identity transformation, the same nanohormones that transform your body are also producing drugs for others. becoming transreal looks at transgender experience through a lens of slipstream science fiction poetry about bio-nano drug piracy. The performance uses motion capture to interface with Second Life avatars [http://en.wikipedia.org/wiki/Second_Life] and 3D stereoscopic imagery to immerse the audience in this transreal world.

Cárdenas operates in the tradition of mixed-reality performance, which Steve Benford and Gabriella Giannachi define broadly as a subset of performance art, including augmented reality and pervasive gaming, that combine "many real, virtual, augmented reality, and augmented virtuality environments into complex hybrid and distributed performance stages" (3). Although many mixed-reality works, such as Blast Theory's Uncle Roy Everywhere or 42 Entertainment's 
I Love Bees, focus on direct user participation and mobile technologies, Cárdenas invites the audience to enter the world of the performance through indirect means such as audience props and immersive presentation technologies. Using large-scale projection equipment and biometric sensors keyed to the performers' bodies, Cárdenas's transreal performances bridge a physical installation space with the virtual world of Second Life, (dis)embodying their own content through form. Cárdenas creates a performance space and temporality layered with autobiography and speculative fiction, physical bodies and digital avatars.

[Video by Micha Cárdenas and Elle Mehrmand, "Becoming Transreal”: http://vimeo.com/16869351]

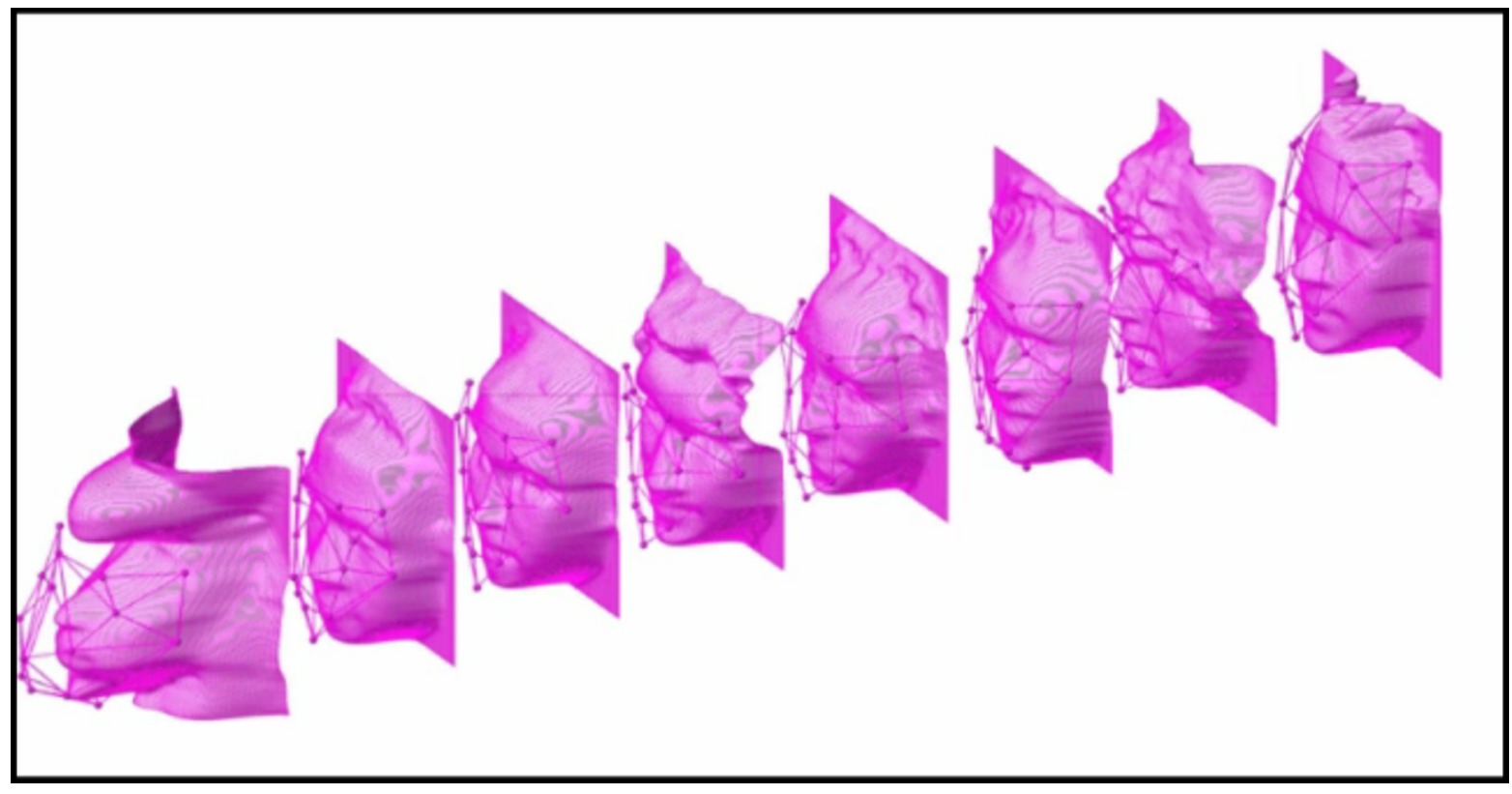

\section{Zach Blas: Queer Technologies}

Zach Blas's Queer Technologies project invites viewers to rethink the role of critical theory by bringing it out of academic language and into the realm of product design. Blas's art reimagines 
queer theory as a high-design brand, building objects that we can imagine as desirable accessories for the discerning plugged-in activist, and challenging us to pay attention to the commodification of art and ideas. Part manifesto, part news report, part critical essay, Queer Technologies' suite of instructional videos takes digital production as both theory and praxis. Each video documents a queer weapon of resistance that responds to, yet participates in, the methods of the technological tools of empire. Blas's playful, speculative products ironically reproduce the signifiers of global capital while offering queer possibilities for undermining them, as indicated by the promotional speech embedded in each video:

Queer Technologies is an organization that develops applications for queer technological agency, interventions, and social formation. We use technology to make queer weapons of resistance. These include: transCoder, a queer programming anti-language software development kit; ENgendering Gender Changers, a solution to gender adapters' male/female binary; Gay Bombs, a technical manual manifesto that outlines a how-to of queer networked activism; and GRID, a mapping application that tracks dissemination of queer technologies and maps the battle plans to more thoroughly infect networks of global capital. You can find our products at the Disingenuous Bar, a center for political support for technical problems, or in various consumer electronics stores, such as Best Buy, Radio Shack, and Target.

This sarcastic PR spin calls into question the Apple products and slick gadgetry on which mediainclined academics depend; indeed, Queer Technologies asks us to consider not only the ends to 
which we apply our digital tools, but also the troubling legacies and potential applications of cutting-edge developments in science and technology.

The video "Fag Face, or How to Escape Your Face" responds to biometric technologies that enlist the face in governmental control systems, whose applications range from commercial digital camera software to surveillance technologies used by local law enforcement. Responding to legacies of homophobia and neoliberal governance with Deleuze, Guattari, and gay pornography, "Fag Face" offers a new way to think about and produce critical theory.

[Video by Zach Blas, "Fag Face": http://vimeo.com/26638452]

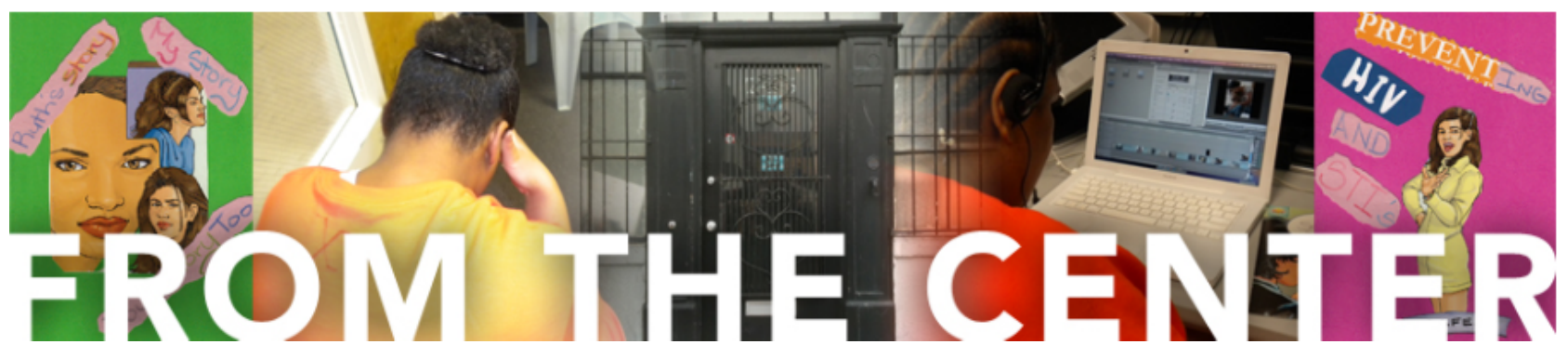

From the Center

Scholarship and activism, academy and community, theory and pedagogy are often considered to be separate. By including this project, in which researchers and technology educators work with incarcerated women of color using digital storytelling techniques, we hope to challenge readers to think about what it might mean to allow our ideas about scholarship and political commitment to be transformed from the ground up. Digital scholar, poet, and University of CaliforniaBerkeley graduate student Margaret Rhee serves as project co-lead and conceptualist. At the 
2011 HASTAC Conference, Rhee spoke of this collaborative activist work as "counterintuitive to the logics and rewards of the academy"-yet absolutely necessary.

As feminists in our new media age, we believe women should be the authors, directors and storytellers of our own lives. We re-imagine how new media technologies can provide a vital intervention for all women, even those whose voices are subsumed in larger hegemonic discourse. Oftentimes, incarcerated women and issues of race, class and sexuality are unacknowledged even in interdisciplinary areas such as Ethnic, Women and Queer Studies and in larger conversations and decisions of HIV/AIDS prevention education, policy and new media technologies. "From the Center" derives from intersectional issues, domains and disciplines. We hope to bridge seemingly disparate subjects: feminist praxis, HIV/AIDS education, digital storytelling, the prison industrial complex, Women's Studies, Ethnic Studies and New Media Studies. Thus, we question, hope and urge a re-articulation of women's identity, HIV/AIDS education and the digital divide by centering the issues and concerns of incarcerated women. (From the Center)

The field of digital humanities has become well known for its willingness to challenge academic conventions on one level: the idea that a $\mathrm{PhD}$ constitutes professional training that should lead invariably to a tenure-track university teaching position. Yet the vision of From the Center, and Rhee's insistence that her work should be considered part of a scholarly project, highlights the limits of the academic transformations suggested by the increasingly celebrated alt-ac narrative (which encourages PhDs to seek careers in non-teaching roles in the university). From the Center is a far more radical vision of what alternative scholarly knowledge projects and professional 
practices could be. It is not uncommon for scholars with particular political commitments to use their skills for activist projects in addition to their university work of teaching, research, and (in the age of DH) digital projects. But what would it mean to slip the bounds of the neoliberal academy, even for a moment, and imagine this work as the center of scholarly activity?

[Digital story, "Miracle": http://vimeo.com/26096719]

Because I want to help women know that it is okay to go through things like that, this life. Because I have someone in my family who has HIV. And I learned from her how to have safe sex and get tested.

From the evocative intensity of the video to the straightforward statements that highlight a reality too rarely acknowledged within scholarly spaces, knowledge is being produced and transmitted here. When From the Center's team travels to conferences, its presenters include formerly incarcerated participants as well as academics and professional activists. Their presence suggests that the privileged sphere of digital scholarship need not remain hermetically sealed from those who "go through things like that, this life."

\section{Transformative Networked Pedagogies}

Connections and support networks among those engaged in knowledge production are central to the growth of the digital humanities sphere. Much unacknowledged work of consolidation, mentorship, and intellectual framing takes place in and through digitally mediated social 
networks. Here we highlight two examples that make the work of theory/practice explicit and conscious, building collaborative spheres on feminist principles and connecting transformative praxes inside and outside the academy.

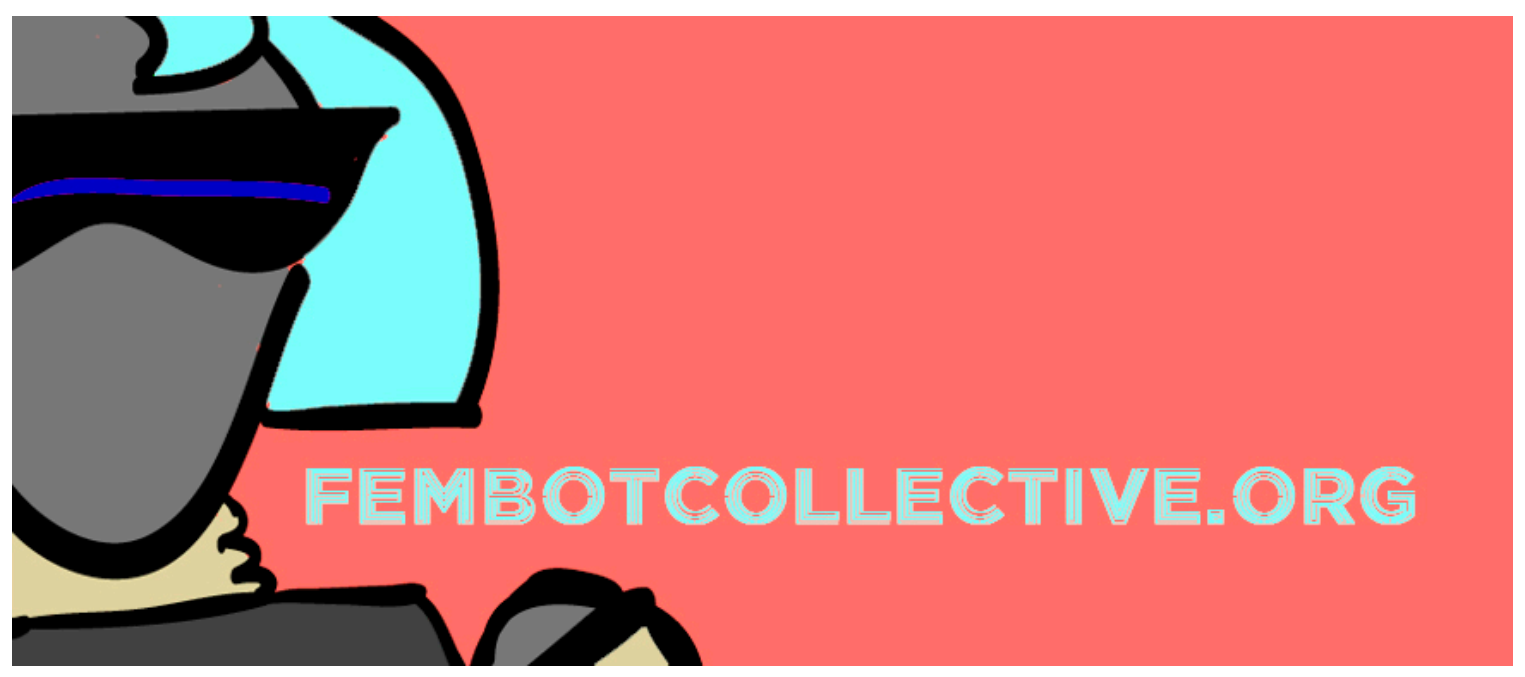

Fembot Collective: Feminism, New Media, Science and Technology

The Fembot Collective consists of faculty, graduate students, and librarians who created a portal for feminist scholarship about technology. Committed to the ideals of open source, Fembot hosts an online journal, Ada: Journal of Gender, New Media and Technology, with an open peer editorial process, an expanded notion of what "article" means, and a built-in system to help contributors bolster promotion and tenure portfolios:

Fembot has developed a framework for a two-level review process that includes an open editorial peer review and a community level of review for works in progress. Valuing both the scholarly works and participation in the community of review, Fembot will 
provide metrics on article views/downloads and the usefulness of comments. These metrics will be aggregated into a portfolio, which is conducive to forming an incentive to participate in the community and support an argument for value toward promotion.

In addition to its transformation of scholarly publishing, Fembot contributes pedagogical tools on the undergraduate and graduate levels, hosting blog posts in the site's Laundry Day section that outline short, teachable moments in feminist technology scholarship, and providing tenure policies and dissertation prospectuses for use in professionalization training.

Most recently, Fembot acts as the portal for FemTechNet, a feminist technology teaching network that hopes to launch a course taught worldwide, Dialogues on Feminism and Technology, in 2013. Billed as a "Distributed Online Collaborative Course," FemTechNet is an attempt at developing a viable model for transdisciplinary, transnational, transmedial collaborative pedagogies, and a feminist intervention on the MOOC (Massive Open Online Course) model that is prevalent and controversial in current digital humanities discourse. In the future, Fembot will host peer-evaluated readings, videos, bibliographies, and other teaching resources to aid participants in tailoring local instances of the course to its networked goals. Experiments such as FemTechNet and $A d a$ position the Fembot Collective as an innovator in scholarly communicative possibilities.

\section{THE GRUNK FEMINIST COLIEGTIVE}

Crunk Feminist Collective "Mission Statement" 
In its mission statement, the Crunk Feminist Collective throws off "hegemonic ways of being" in favor of reveling in and sharing the intoxicating effects of women of color feminisms with its readership and commenting community. This blogging community provides a space for women of color to commune, critique, and call out hegemonic culture in ways that reach across the divide separating academia from the popular.

Beat-driven and bass-laden, Crunk music blends Hip Hop culture and Southern Black culture in ways that are sometimes seamless, but more often dissonant. Its location as part of Southern Black culture references the South both as the location that brought many of us together and as the place where many of us still do vibrant and important intellectual and political work. The term "Crunk" was initially coined from a contraction of "crazy" or "chronic" (weed) and "drunk" and was used to describe a state of uberintoxication, where a person is "crazy drunk, " out of their right mind, and under the influence. But where merely getting crunk signaled that you were out of your mind, a crunk feminist mode of resistance will help you get your mind right, as they say in the South.

Casting off stilted academic speech for lyrical manifestos, insisting on the utility of affect for deep and considered arguments, and refusing to disconnect deeply personal stories from the project of scholarship, the Crunk Feminists' commentary is more timely than journal production and more effective in enlisting the passion and drive of reader-students for social justice purposes. 
The collective's interventions in internet and popular culture have included critiquing mainstream media for its coverage of Olympians Gabby Douglas and Claressa Fields, covering the triumphs and missteps of the popular The Misadventures of Awkward Black Girl web series, and offering film and television reviews that range from Love and Hip Hop to Pariah. The Crunk Feminists also offer practical career advice for young academics and swap experiences and strategies for the unique struggles of the black feminist running a university-level class. As the blog's large community of regular readers and commenters attest, the tactics and philosophies of Crunk Feminism reach into academia and beyond, educating and transforming their corner of the web.

\section{Conclusion}

As the tools and methods of the digital humanities take up their new positions of prominence, we can only hope that they will begin to take on the mutations and instabilities represented by the practitioners and projects featured here, rather than settle into the creaky machine of the corporate university. Whatever its future, DH has already proved its power to unsettle the old guard, inducing anxious and skeptical blog posts from high-profile critics and me-too conference panels spreading the word to far-off disciplines. The spirit of \#transformDH is not to arrest this momentum, but to channel it in truly transformative directions - to avoid trading whiteness for more whiteness, heteropatriarchy for more heteropatriarchy, one imperialist hierarchy for another. We hope the community at large will continue to find and go viral with the social justice-minded hybrid practices, identities, and collaborations elaborated in McPherson's epigraph to this work 
of curation and analysis - the antiracist archives, the queer art-theories, the collaborative feminist pedagogies, the crunk academic activisms, the critical race coders. \#TransformDH is a convenient means to do so, but in the spirit of transformative work, we hope it will be supplanted by something else soon.

\section{About the Authors}

Alexis Lothian is assistant professor of English at Indiana University of Pennsylvania, where she researches and teaches at the intersections of cultural studies, digital media, speculative fiction, and queer theory. She is the editor of an upcoming special issue of Ada: Journal of Gender, New Media and Technology on feminist science fiction, a coeditor of a Social Text Periscope dossier on Speculative Life, and a founding member of the editorial team for the journal Transformative Works and Cultures. Her work has been published in International Journal of Cultural Studies, Cinema Journal, Camera Obscura, and Journal of Digital Humanities.

Amanda Phillips is a PhD candidate in the Department of English with an emphasis in feminist studies at the University of California-Santa Barbara. Her dissertation takes a vertical slice of the video games industry to look at how difference is produced and policed on multiple levels of the gamic system. Her interests more broadly are in queer, feminist, and race-conscious discourses in and around technoculture, popular media, and the digital humanities. In addition to participating in the Humanities Gaming Institute 2010, sponsored by the National Endowment for the Humanities (NEH), Amanda has been a HASTAC Scholar since 2009; she has also hosted, in conjunction with Margaret Rhee, an online HASTAC forum on Queer and Feminist New Media 
Spaces, the organization's most commented on forum to date. She has presented at the conferences for UCLA Queer Studies, the American Studies Association, the Modern Language Association, the Popular Culture Association, and the Conference on College Composition and Communication, and has participated in unconferences such as HASTAC's Peer-to-Peer Pedagogy Workshop, THATCamp SoCal, and the Transcriptions Research Slam. Most recently, she has been involved with the \#transformDH Collective's efforts to encourage and highlight critical cultural studies work in digital humanities projects.

\section{Bibliography}

Benford, Steve, and Gabriella Giannachi. Performing Mixed Reality. Cambridge, MA: MIT Press, 2011.

Blas, Zach. "Fag Face, or How to Escape Your Face.”Vimeo. 2012. Accessed May 9, 2012. http://vimeo.com/26638452.

—_. “Queer Technologies: Automating Perverse Possibilities.” Queer Technologies. 2012. Accessed May 9, 2012. http://www.zachblas.info/projects/queer-technologies/.

Cárdenas, Micha. Transreal.org. 2012. Accessed May 9, 2012. http://transreal.org/.

Cárdenas, Micha, and Elle Mehrmand. "Becoming Transreal.” UCLA Freud Playhouse, Los Angeles, CA. Performed Nov. 3, 2010. Vimeo. May 9, 2012.

The Crunk Feminist Collective. The Crunk Feminist Collective. 2010-present. Accessed May 9, 2012. http://crunkfeministcollective.wordpress.com/.

__. "Mission Statement." The Crunk Feminist Collective (blog). Mar. 6, 2010. Accessed May 9, 2012. http://crunkfeministcollective.wordpress.com/about/. 
The Fembot Collective. Fembot: Feminism, New Media, Science and Technology. 2012. Accessed May 9, 2012. http://fembotcollective.org/.

Gold, Matthew K. "Whose Revolution? Towards a More Equitable Digital Humanities." The Lapland Chronicles (blog). Jan. 10, 2012. Accessed May 9, 2012. http://mkgold.net/blog/2012/01/10/whose-revolution-toward-a-more-equitable-digitalhumanities/.

González, Isela, Margaret Rhee, Allyse Gray, and Kate Monico Klein. From the Center: Facilitating Feminist Digital Theory and Praxis in a Digital Environment (blog). 2012. Accessed May 9, 2012. http://hastac.org/blogs/alexislothian/2011/12/02/hastac2011center-facilitating-feminist-digital-theory-and-praxis-dig.

Graduates of From the Center. "Miracle." Vimeo. 2010. Accessed May 9, 2012. http://vimeo.com/26096719.

Juhasz, Alex. “Two Conferences: One Students'/Women's Media Power.” Media Praxis: Integrating Media Theory, Practice and Politics (blog). Apr. 2, 2012. Accessed May 9, 2012. http://aljean.wordpress.com/2012/04/02/two-conferences-one-studentswomensmedia-power/.

Koh, Adeline. "Addressing Archival Silence on 19th Century Colonialism - Part 1: The Power of the Archive." Adeline Koh (blog). Mar. 4, 2012. Accessed May 9, 2012. http://www.adelinekoh.org/blog/2012/03/04/addressing-archival-silence-on-19th-centurycolonialism-part-1-the-power-of-the-archive/.

— . "Addressing Archival Silence on 19th Century Colonialism - Part 2: Creating a Nineteenth Century 'Postcolonial’ Archive.” Adeline Koh (blog). Mar. 4, 2012. Accessed May 9, 
2012). http://www.adelinekoh.org/blog/2012/03/04/addressing-archival-silence-on-19th-centurycolonialism-part-2-creating-a-nineteenth-century-postcolonial-archive/.

. Digitizing “Chinese Englishmen.” 2012. Accessed May 9, 2012.

http://chineseenglishmen.adelinekoh.org/.

Macklin, Angelica. “I Saw You On The Radio!” Vimeo. 2011. Accessed May 9, 2012.

http://vimeo.com/24484214.

McPherson, Tara. "Why is the Digital Humanities So White?, or, Thinking the Histories of Race and Computation." In Debates in the Digital Humanities, edited by Matthew K. Gold, 138-160. Minneapolis: Minnesota University Press, 2012.

Women Who Rock Project: Making Scenes, Building Communities. 2012. Accessed May 9, 2012. http://womenwhorockcommunity.org/.

Published by the Dartmouth College Library. http://journals.dartmouth.edu/joems/

Article DOI: 10.1349/PS1.1938-6060.A.425

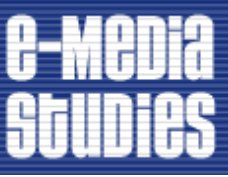

